México D. F., 26 y 27 de junio de 2014

\title{
Coloquio Internacional «América Latina y la Primera Guerra Mundial. Una historia conectada»
}

México D. F., 26 y 27 de junio de 2014

\section{Gérard Borras}

\section{OpenEdition}

\section{Journals}

Edición electrónica

URL: http://journals.openedition.org/bifea/5305

DOI: 10.4000/bifea.5305

ISSN: 2076-5827

\section{Editor}

Institut Français d'Études Andines

\section{Edición impresa}

Fecha de publicación: 1 agosto 2014

Paginación: 388-394

ISSN: 0303-7495

\section{Referencia electrónica}

Gérard Borras, « Coloquio Internacional «América Latina y la Primera Guerra Mundial. Una historia conectada» », Bulletin de l'Institut français d'études andines [En línea], 43 (2) | 2014, Publicado el 08 agosto 2014, consultado el 05 noviembre 2020. URL : http://journals.openedition.org/bifea/5305 DOl : https://doi.org/10.4000/bifea.5305

Les contenus du Bulletin de l'Institut français d'études andines sont mis à disposition selon les termes de la licence Creative Commons Attribution - Pas d'Utilisation Commerciale - Pas de Modification 4.0 International. 


\title{
COLOQUIO INTERNACIONAL «AMÉRICA LATINA Y LA PRIMERA GUERRA MUNDIAL. UNA HISTORIA CONECTADA»1
}

\author{
México D. F., 26 y 27 de junio de 2014
}

El 26 y 27 de junio, el Centro de Estudios Mexicanos y Centroamericanos (CEMCA), el Instituto Francés de Estudios Andinos y el Institut des Hautes Etudes de I'Amérique latine (IHEAL), con el apoyo de múltiples instituciones como el Institut Français y su fondo d'Alembert, la Casa de Velázquez, el Colegio de México, el Conacyt, organizaron en la ciudad de México un coloquio internacional sobre «América latina y la Primera Guerra Mundial. Una historia conectada».

El coloquio se desarrolló en las excepcionales instalaciones de la biblioteca José Vasconcelos en el Distrito Federal. Fue inaugurado por su excelencia la señora Elisabeth Beton Delègue, embajadora de Francia en México y por Fernando Álvarez del Castillo, director general de Bibliotecas de Conaculta. Ana Carolina Ibarra González, directora del Instituto de Investigaciones Históricas de la UNAM y Erika Pani Bano, directora del Centro de Estudios históricos del Colegio de México intervinieron para resaltar la importancia del tema y el placer de poder compartir estos espacios científicos con las diferentes instituciones presentes. Delphine Mercier, directora del CEMCA y Olivier Compagnon profesor de la universidad Sorbonne Nouvelle Paris3 dieron la bienvenida y presentaron el marco científico del coloquio.

La justificación del evento iba más allá de la fecha aniversario. Según rezaba la presentación existía un desfase grande entre lo que representó la Primera Guerra Mundial en Europa y Estados Unidos y la atención que mereció por parte de los historiadores en América Latina, donde «solo dio lugar a escasos trabajos exploratorios». El propósito del coloquio era, justamente reevaluar la importancia que los años 1914-1918 tuvieron en la historia contemporánea de América Latina. Para proponer esta nueva lectura los responsables científicos del evento organizaron 4 mesas temáticas con sus respectivos comentaristas.

La conferencia inaugural titulada «Geographies of belligerence. Towards a global history of the First World War» estuvo a cargo de Pierre Purseigle de la Universidad de Warwick. Empezó indicando cómo, al conmemorar el centenario del estallido de la Primera Guerra Mundial en 2014, la historia global del conflicto está todavía por escribirse y cómo la historiografía de la Primera Guerra Mundial sigue siendo marcada por el continuo predominio de las perspectivas nacionales y eurocéntricas. La cronología convencional de la guerra (1914-1918) es otra herencia de la historia diplomática y militar convencional. Trabajos recientes han hecho hincapié en la necesidad de colocar la Primera Guerra Mundial en un marco cronológico más amplio (1911-1923); en un continuo de conflictos coloniales, las guerras europeas, las guerras civiles, revoluciones, violencia política y genocidio. Pierre Purseigle

${ }^{1}$ Este informe de evento ha sido realizado en base a los resúmenes de los diferentes conferencistas. 
presentó los contornos de una geografía histórica de la guerra que podría mejorar nuestra comprensión de la totalización y globalizar la lógica de la Primera Guerra Mundial. Atentos a la intensidad variable y extensión del conflicto, a los flujos globales de recursos humanos y materiales, así como a los impactos ambientales y culturales del conflicto, este enfoque puede ayudar a repensar la experiencia de combate, la movilización, y reconstrucciones y entender mejor la Gran Guerra, 100 años después.

La primera mesa «Guerra y vida política» centró su lectura sobre el caso de México, tratando de descifrar el impacto de la Gran Guerra en este país. Álvaro Matute y Jean Meyer fueron los comentaristas. Javier Garciadiego, de El Colegio de México (COLMEX), dedicó su charla a las relaciones entre la revolución mexicana y el gran conflicto europeo que a pesar de la distancia se pueden leer como dos procesos conexos de gran influencia mutua. Romain Robinet de SciencesPo Paris, por su parte presentó una investigación sobre el impacto de la Gran Guerra en las asambleas políticas del México de la Revolución.

La Gran Guerra, con su monstruoso espectáculo, no solo fue una preocupación central de la diplomacia mexicana. El espectro de la «guerra europea» se inmiscuyó también en las asambleas revolucionarias. Así, los debates del Congreso Constituyente y de la Cámara de Diputados estuvieron regularmente salpicados de referencias bélicas. El conflicto de 1914-1918, evento lejano pero ensordecedor, agudizó las posiciones previas de los actores políticos que, a través de sus decisiones, orientaban la Revolución. De este modo, la «guerra europea» fue en reiteradas ocasiones el argumento decisivo para terminar de tajo los múltiples debates que agitaban el mundo político revolucionario, ya fueran sobre el papel de los civiles, el nacionalismo, el latinoamericanismo, el socialismo o la educación. Si la Revolución Mexicana puede ser considerada como la primera revolución del siglo XX es de cierto modo porque sus intérpretes la orientaron en aquel entonces observando detenidamente la pesadilla europea. Guillemette Martin, del Instituto de Investigaciones Históricas de la UNAM nos invitó a pensar sobre la importancia de la prensa regional en el contexto del conflicto. A partir de una doble pregunta: ¿qué espacio ocupa realmente la Primera Guerra Mundial en el debate público regional? Y, ¿cuáles son los aportes del análisis regional para reevaluar el impacto cultural e intelectual de la Gran Guerra en México? Para tratar de contestar estas preguntas, se 
analizó de manera comparada la prensa publicada en Guadalajara, capital de Jalisco y segunda ciudad del país, y en Mérida, capital de Yucatán. Guillemette Martin reveló así una movilización original del discurso local sobre la Guerra, sobre todo a partir de la entrada de los Estados Unidos en el conflicto, en 1917.

La segunda mesa temática llevada a cabo el jueves 26 estuvo dedicada a las «Reconfiguraciones identitarias y diplomáticas» provocadas por el conflicto y contó con los comentarios de Lorenzo Meyer. David Marcilhacy, de la Universidad ParisSorbonne presentó el caso de «España y América Latina ante la Gran Guerra: el frente de los neutrales». El ponente mostró cómo al estallar el conflicto el mundo hispano no se encontraba en condiciones de participar directamente en el conflicto. Sin verdaderas capacidades militares y con opiniones públicas divididas entre aliadófilos y germanófilos, la mayoría de sus gobiernos se decantaron por la neutralidad. En este contexto, la diplomacia y las elites españolas pronto vieron el beneficio que podía sacar su país de esta convergencia con las naciones «hermanas» de América, para compensar su retraimiento internacional y fomentar el comercio, aprovechando la coyuntura bélica. Así vino a constituirse una forma de bloque latino entre los neutrales, del que España pretendió ser el portavoz en el continente europeo. A partir de ahí, se fue construyendo un eje España/ América Latina, en el que florecieron las iniciativas de cooperación y los discursos de solidaridad trasatlántica. Mientras muchos latinoamericanos pretendían así desmarcarse de la hegemonía norteamericana y proclamar su rechazo a la barbarie de la contienda europea, para los españoles este programa suponía potenciar la corriente hispanoamericanista y preparar los nuevos equilibrios mundiales que surgirían en la posguerra. Finalmente, David Marcilhacy, mostró cómo, al calor de la fraternidad «racial» demostrada ante el conflicto, fue surgiendo un nuevo relato sobre la comunidad de destino entre España y sus ex colonias americanas, y esos años de crisis de la civilización europea favorecieron un despertar identitario en el mundo hispano que condicionaría la geopolítica de las siguientes décadas.

María Inés Tato de la Universidad de Buenos Aires y del CONYCET presentó una reflexión en torno al impacto de la gran guerra en Argentina bajo el título «¿̇Latinos, hispanos, americanos? La Gran Guerra y la "cuestión nacional" en la Argentina». Mostró cómo la Primera Guerra Mundial tuvo una honda repercusión en Argentina, históricamente vinculada a Europa por lazos culturales, económicos y demográficos. A lo largo de la contienda la sociedad argentina fue protagonista de una intensa movilización cultural y política que puso de manifiesto una activa toma de partido y un fuerte compromiso en torno de uno u otro de los bandos beligerantes. La crisis civilizatoria europea engendrada por la Gran Guerra no podía resultar indiferente a una sociedad que encontraba en el Viejo Mundo a sus principales referentes culturales e ideológicos desde los tiempos de la independencia. En esta ponencia, María Inés Tato exploró la apelación a identidades trasnacionales alternativas que circularon en Argentina en el transcurso de la guerra y que fueron claves en la movilización de la lealtad de la opinión pública en torno a las naciones en lucha. El latinismo, el hispanismo y el americanismo proponían insertar a la argentinidad dentro de configuraciones 
identitarias más amplias que trascendían sus fronteras, estimulando la militancia alrededor de la guerra y reavivando una nueva reflexión sobre la definición de la nacionalidad. María Fernanda Rollo de la Universidad de Lisboa, presentó una charla sobre lo que representó el conflicto para Portugal bajo el título «Portugal and Latin America at the crossroads of global war».

Xavier Calmettes de la Universidad Sorbonne Nouvelle - Paris 3 observó el caso de Cuba en el contexto del conflicto. Impartió una charla sobre «La sociedad cubana ante Europa y los Estados Unidos durante la Primera Guerra Mundial» para mostrar cómo el conflicto mundial constituyó una ruptura de las representaciones del mundo exterior de los cubanos. Aunque alejada de los campos de batalla europeos, esta sociedad caribeña vivió la Primera Guerra Mundial a través de lo que vivían soldados y enfermeras cubanos enviados a los frentes europeos, a través de los relatos de inmigrantes, de la noticias procedentes de Europa y de su diplomacia. La contienda cambió las representaciones que los actores tenían de Europa y de Estados Unidos, al mismo tiempo que acarreó trastornos de orden económico y social que estimularon el desarrollo de un poderoso movimiento nacionalista en Cuba.

La tercera mesa 3 temática realizada el viernes 27 de junio tuvo por tema central las economías latinoamericanas frente al conflicto y contó con los comentarios de Leonor Ludlow. Phillip Dehne, del St. Joseph's College de Nueva York dio su charla sobre «Placing Latin America into Britain's global strategy». Mostró cómo la guerra invirtió, en parte, los tradicionales intercambios económicos entre los dos espacios ya que los estados latinoamericanos ganaron importancia estratégica en este contexto bélico. Explicó también cómo la guerra hizo más complejas las relaciones entre Estados Unidos y Gran Bretaña. Mediante la utilización de fuentes de las empresas y los funcionarios británicos, este trabajo aporta nuevos datos sobre el lugar central de las repúblicas latinoamericanas durante la Primera Guerra Mundial.

Carlos Contreras Carranza, de la Pontificia Universidad Católica del Perú, centró su lectura sobre un caso particular: el del Perú, con su ponencia «La Gran Guerra y la economía peruana, 1914-1920». La guerra tuvo dos impactos diferentes en las economías latinoamericanas. Por una parte, las economías crecieron ante la demanda de insumos bélicos y sus industrias locales resultaron protegidas de la competencia de las importaciones provenientes del mundo desarrollado. Sin embargo, también surgen otras complicaciones, derivadas de la interrupción del flujo de capitales y del acceso a ciertos insumos claves para las exportaciones y las industrias locales, por lo que evaluar las consecuencias de dichas guerras resulta siempre complejo. La ponencia trató de esclarecer el caso peruano con ocasión de la gran guerra europea o Primera Guerra Mundial de 1914-1918.

Sandra Kuntz Ficker del Colegio de México habló de la situación particular de México y de su «contribución a la causa de los aliados durante la Primera Guerra Mundial». En efecto, México contribuyó a la causa de los Aliados por la vía del comercio, mediante la provisión de bienes estratégicos a Gran Bretaña, Francia y Estados Unidos. Es un fenómeno paradójico si se considera 
el antagonismo permanente de Gran Bretaña respecto al líder de la facción que resultaría triunfante en la revolución, Venustiano Carranza, y al gobierno que luego él mismo encabezó, y las tensiones que por distintas causas permeaban las relaciones con Estados Unidos. También resulta difícil de explicar a la luz de las simpatías que el propio Carranza y sus colaboradores más cercanos parecían profesar a Alemania y que esta correspondía, materializadas en conversaciones y propuestas que se hicieron públicas en esos mismos días. En cualquier caso, resulta relevante tratar de explicar si esa contribución se produjo debido a una decisión deliberada por parte de los líderes mexicanos; si, en cambio, fue el resultado de la «condescendencia pasiva» que mostraron respecto a la problemática de la guerra, o si fue más bien una ironía de la historia, o más precisamente, un hecho involuntario debido a circunstancias que escapaban de su control. Describir la naturaleza de esa contribución e intentar explicar las razones de esta ironía han sido el propósito de este trabajo.

Mario Cerutti, de la Universidad Autónoma de Nuevo León en México dedicó su intervención al caso particular de las economías regionales con una charla sobre el tema «Monterrey y el noreste durante las dos guerras mundiales (1914-1945). Impactos sobre la actividad empresarial». La Primera Guerra Mundial no parece haber tenido impactos favorables sobre gran parte de la economía mexicana, como se habría manifestado en otras áreas de América Latina y, en la Europa neutral, en la economía española. La causa principal fue que México se encontraba en plena revolución. Buena parte del norte del país, y el noreste en particular, mostraron esa situación de manera evidente. En Monterrey y su entorno algunas de las empresas fabriles fundadas durante el porfiriato se vieron afectadas, y hasta algunas (como Cementos Hidalgo) dejaron de operar. Fundidora de Fierro y Acero, por su lado, sobrevivió gracias a sus oscilantes exportaciones de acero. En La Laguna la ruda lucha entre ejércitos afectó de manera sustancial la actividad agroindustrial ante las acciones de Francisco Villa y sus tendencias confiscatorias. Un panorama muy distinto se perfiló durante la Segunda Guerra. En Monterrey, la natalidad empresarial se multiplicó entre 1940 y 1945, las exportaciones de fibra desde Tamaulipas crecieron abruptamente y en La Laguna la economía del algodón entró en una de sus fases más recordadas. La ponencia procurará comparar los impactos que sobre la actividad empresarial de ciertos sectores básicos tuvieron ambas contiendas y, de paso, dejará en evidencia lo estratégico que para el norte mexicano era la siempre usufructuable vecindad territorial con los Estados Unidos.

La cuarta mesa, desarrollada el viernes 27 de junio, estuvo dedicada a la dimensión social y cultural de la guerra y tuvo como comentarista a María Inés Tato. Gérard Borras, del Instituto Francés de Estudios Andinos presentó una ponencia sobre el impacto de la guerra en la vida de la sociedad peruana de aquel entonces: «Moi mon colon celle qu'je préfère... Entre objetos musicales, imágenes y versos. Recepciones de la conflagración europea en Lima (1914-1918)». La comunicación trató de mostrar cómo estratos de la sociedad peruana vivieron estos efectos del conflicto y cómo a través de diferentes medios expresaron sus sentimientos. Las partituras, las canciones, los cancioneros, pero también las poesías y las imágenes dan elementos para poder entrever «sensibilidades» que atravesaban la sociedad 


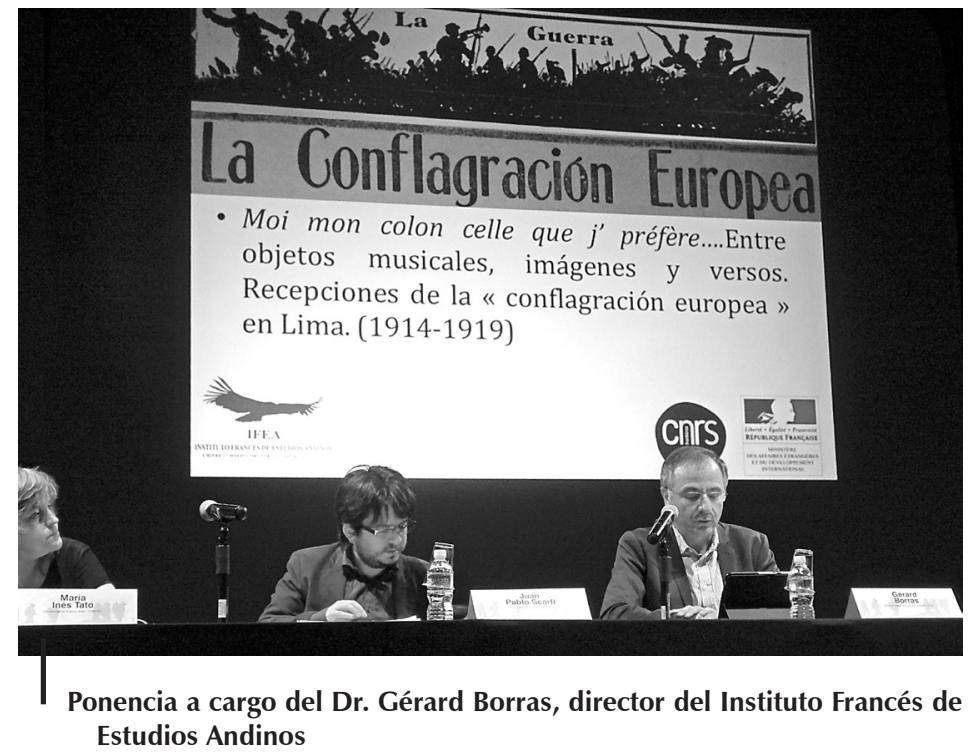

peruana — limeña en gran parte — en este momento trágico de la historia mundial. Valentin Kramer de la Universidad Católica Eischstätt-Ingolstadt mostró el papel de las sociabilidades en tiempo de guerra con una charla sobre el tema «Beneficencia patriótica: Asociaciones de mujeres alemanas en Rosario, 1914-1924». Las sociedades religiosas y benéficas eran dos de los pocos espacios socialmente aceptados para iniciativas femeninas independientes. Pero las mujeres poseían un acceso limitado a las asociaciones étnicas de la «colonia» o, incluso, carecían del mismo, sobre todo en lo que respecta a membresía y funciones directivas. Durante, e incluso, tras el fin de la Primera Guerra Mundial, las mujeres alemanas en Rosario intensificaron sus actividades en dichas áreas, recaudando donativos para la «patria» en nuevas asociaciones patrióticas y fomentando instituciones caritativas locales. De esta manera, ellas ganaron en importancia en los entornos patriarcales del asociacionismo alemán, pero sin poder cuestionar imágenes de mujeres establecidas.

Juan Pablo Scarfi, de la Universidad de Cambridge, intervino sobre temas de derecho con una conferencia cuyo título fue «El pensamiento legal internacional latinoamericano ante la Primera Guerra Mundial: el nuevo derecho internacional americano, el panamericanismo y el renacimiento del latinoamericanismo defensivo (1914-1933)». Con esta ponencia se analizó el impacto de la Primera Guerra Mundial en el pensamiento legal internacional latinoamericano y la construcción de propuestas legales hemisféricas (panamericanas) y regionales (latinoamericanas) para la región y para la reconstrucción del nuevo orden mundial resultante de la Gran Guerra. Juan Pablo Scarfi se enfocó fundamentalmente en juristas y especialistas en derecho internacional y también en figuras intelectuales, políticas y diplomáticas, como Alejandro Álvarez (Chile), Ruy Barbosa (Brasil), Carlos Saavedra 
Lamas (Argentina), César Díaz Cisneros (Argentina), Baltasar Brum (Uruguay) e Isidro Fabela (México), explorando cómo estas figuras respondieron a los desafíos presentados por la Gran Guerra entre los años que van desde 1915 hasta 1933, y cómo concibieron y reaccionaron frente al nuevo orden internacional resultante del conflicto. Mostró cómo la actitud predominante de los juristas latinoamericanos estuvo dominada, por un lado, por el desencanto y el distanciamiento respecto de Europa, un continente que comenzó a asociarse por entonces con la competencia imperialista, el balance de poderes y la guerra, y, por otro lado, por la defensa de un derecho internacional americano y de los ideales del panamericanismo. Sin embargo, como se intentará mostrar, algunos juristas mexicanos y argentinos concibieron un nuevo orden legal mundial diferente, donde Europa debía ocupar un lugar importante para América Latina, respaldando la paz y el regionalismo latinoamericanista para contrapesar la creciente influencia hegemónica que comenzó a ejercer Estados Unidos a partir de 1914, y ciertamente luego de la Gran Guerra, en el ámbito del derecho internacional y la diplomacia continental.

Emilio Zamora, de la universidad de Texas-Austin, intervino sobre el tema «Los México Americanos en La Gran Guerra. El Diario de José de la Luz Sáenz». La narración que publica el profesor José de la Luz Sáenz, soldado que prestó sus servicios en el Regimiento 360 de infantería de las fuerzas expedicionarias en Francia, es el único diario de guerra escrito por un soldado norteamericano de origen mexicano. Narra los acontecimientos en los campos de entrenamiento y batalla desde el 25 de febrero de 1918 hasta el 21 de junio de 1919. No solo presenta las experiencias difíciles y semblanzas heroicas de mexicanos que se distinguen en la lucha armada, también expresa una visión de la guerra como forma de explotación y como una oportunidad para promover los intereses de los mexicanos en Estados Unidos. Respecto a la guerra como forma de explotación, Sáenz expresa la opinión común entre los mexicanos que la sociedad norteamericano los menosprecia menos cuando los necesita como carne de cañón. La guerra, según Sáenz, también presenta a los mexicanos la oportunidad de demostrar su valía a la Nación para después reclamar igualdad en la lucha en pro de derechos civiles. Sáenz expone sus opiniones emancipadoras en el diario así como en el periodo después de la guerra, a través de organizaciones como La Liga de Ciudadanos Latinoamericanos Unidos.

El coloquio terminó con la conferencia de clausura de Olivier Compagnon de la Universidad Sorbonne Nouvelle - Paris 3 (IHEAL), titulada «La Gran Guerra y la historiografía del siglo XX latinoamericano». Sobre la base de los trabajos presentados en el coloquio y de varios estudios recientes, Olivier Compagnon puso en evidencia las razones que explican la ausencia del periodo 1914-1918 en la historiografía de América Latina. Examinó la posibilidad de escribir una historia comparada de la Primera Guerra Mundial al sur del Río Bravo y propuso una reflexión sobre las cronologías alternativas del siglo XX latinoamericano, que esta reevaluación de la Gran Guerra podría suscitar. 